\title{
Antipsychotic Effects of Quetiapine in Naturalistic Long Term Follow Up Study
}

\author{
Jung-Sun Lee ${ }^{1}$, Joon Ho Ahn ${ }^{2}$ \\ Do-Hoon Kim ${ }^{3}$, Jong-Jin Kim ${ }^{4}$ \\ Tae-Young Kim ${ }^{5}$, So-Young Yoo ${ }^{6}$ \\ Dong-Geun Lee ${ }^{7}$, Sang-Hyuk Lee \\ Se-Won Lim ${ }^{9}$, Weon-Jeong Lim ${ }^{10}$ \\ II-Kyung Jung ${ }^{11}$, Hae-Kyung Jung ${ }^{5}$ \\ Dong-Hwan $\mathrm{Cho}^{12}$, In-Hee $\mathrm{Cho}^{13}$ \\ Chang-Yoon Kim ${ }^{1 凶}$
}

1'Department of Psychiatry,

University of Ulsan College of Medicine,

Asan Medical Center, Seoul,

2Department of Psychiatry,

University of Ulsan College of Medicine,

Ulsan University Hospital, Ulsan,

${ }^{3}$ Department of Neuropsychiatry,

Hallym University Medical Center, Chuncheon

Sacred Heart Hospital, Chuncheon,

${ }^{4}$ Department of Psychiatry, Kangnam St.

Mary's Hospital, College of Medicine,

The Catholic University of Korea, Seoul,

${ }^{5}$ Department of Psychiatry, Seoul Veterans

Hospital, Seoul,

${ }^{6}$ AstraZeneca Korea, Seoul,

${ }^{7}$ Department of Psychiatry,

Ko-Yang Mental Hospital, Goyang,

${ }^{8}$ Department of Psychiatry, Bundang CHA

Hospital, College of Medicine,

CHA University, Seongnam,

'Department of Psychiatry, Kangbuk

Samsung Hospital, Sungkyunkwan

University School of Medicine, Seoul,

${ }^{10}$ Department of Psychiatry, School of

Medicine, Ewha Womans University,

Mokdong Hospital, Seoul,

${ }^{11}$ SeoDaeGuDaeDong Hospital, Daegu,

${ }^{12}$ Department of Neuropsychiatry,

Maryknoll Hospital, Busan,

${ }^{13}$ Department of Psychiatry,

Gachon Medical School, Incheon, Korea

\section{$\triangle$ Correspondence}

Chang-Yoon Kim, MD, PhD

Department of Psychiatry,

University of Ulsan College of Medicine,

Asan Medical Center, 86 Asanbyeongwon-

gil, Songpa-gu, Seoul 138-736, Korea

Tel $+82-2-3010-3410$

Fax +82-2-485-8381

E-mail cykim@amc.seoul.kr

(c) This is an Open Access article distributed under the terms of the Creative Commons Attribution Non-Commercial License (http://creativecommons.org/licenses/by-nc/3.0) which permits unrestricted non-commercial use, distribution, and reproduction in any medium, provided the original work is properly cited.
Objective This study aimed to examine the effectiveness of quetiapine and the effects of dosage relates to its effectiveness on schizophrenia and schizoaffective disorder in a naturalistic setting in Korean people.

Methods This study was a 24-week, open-label, non-comparative, naturalistic study of quetiapine in patients diagnosed with schizophrenia and schizoaffective disorder according to DSM-IV. We stratified the patients into mild [(clinical global impression severity (CGI-S) $<4$ at baseline)] and severe groups (CGI-S $\geq 4$ at baseline). We investigated the response rate, defined as clinical global impression improvement (CGI-I) $\leq 2$, in the severe group and the aggravation rate in the mild group using the last-observation-carried-forward (LOCF) and the Kaplan-Meier method (K-M).

Results During the 24 weeks, 151 (18.4\%) of the participants dropped out of the study. There was a significant decrease in the mean CGI-S score, from $4.5 \pm 1.1$ at baseline to $2.8 \pm$ 1.1 at 24 weeks. The response rate of severe group was $54.5 \%$ (estimated by LOCF) and $73.3 \%$ (K-M estimated) at 24 weeks. All patients who completed the study had taken a mean quetiapine dosage of $507.9 \pm 245.9 \mathrm{mg}$ daily. The decrease of CGI-S score in high-dose group (the maximum dose was $750 \mathrm{mg} / \mathrm{d}$ or above) was statistically significant than that in recommendeddose group (the maximum dose was less than $750 \mathrm{mg} / \mathrm{d}$ ).

Conclusion This study demonstrated the long-term effectiveness of quetiapine in the treatment of schizophrenia and schizoaffective disorder in a naturalistic setting in Korean people. This study suggests that higher than recommended quetiapine dosages could be more effective in some patients.

Psychiatry Investig 2010;7:128-134

Key Words Schizophrenia, Quetiapine, Naturalistic study, High-dose.

Received: February 5, 2010 Revised: April 6, 2010 Accepted: April 9, 2010

Available online: May 4, 2010

\section{Introduction}

Many studies have shown that quetiapine was an effective and well tolerated with comparable efficacy to typical antipsychotics, such as haloperidol. Quetiapine has been superior to placebo in the treatment of schizophrenia, at doses ranging from 50 to $750 \mathrm{mg} / \mathrm{d} .^{1-3}$ Although there has been no difference in the overall efficacy of quetiapine compared to typical antipsychotics in the treatment of schizophrenia, ${ }^{4,5}$ quetiapine has had a positive impact on the important domains of cognitive performance and negative/affective symptoms as well as positive symptoms. ${ }^{1,4,6}$ In addition, recent studies have reported the efficacy of quetiapine to treat mood disorder as well as schizophrenia. ${ }^{7-14}$ Patients with quetiapine showed a lesser prolactin (PRL) increase and reported fewer extrapyramidal symptoms (EPS) than patients with haloperidol. ${ }^{4}$

The results of all the above-mentioned clinical trials suggested that quetiapine might have several advantages over typical antipsychotics in the treatment of schizophrenia and bipolar disorder. However, these clinical trial findings should be applied with caution to the usual care setting, because clinical trials are usually performed in controlled settings, with a limited number of patients, and over the short-term. To complement limitations of clinical trials, na- 
turalistic studies can be done in more patients for a longer period. Published naturalistic studies have reported uncertain results that the effectiveness of quetiapine did not differ from that of other atypical antipsychotics and was actually lower than that of olanzapine. ${ }^{15-17}$

There is also some uncertainty regarding not just the effectiveness of quetiapine but also its optimal dose. Although current prescribing information recommends that quetiapine be administered at doses up to $750 \mathrm{mg} / \mathrm{d}(800 \mathrm{mg} / \mathrm{d}$ in the USA, Canada and Korea), there are some questions about the effective optimal dose of quetiapine in the treatment of schizophrenia. Recently, various published results have suggested that in some patients, dosages higher than recommended amount may be necessary to achieve the full therapeutic effect. ${ }^{18,19}$

This study aimed to examine the overall effectiveness of quetiapine and to explore its optimal dose in the treatment of schizophrenia and schizoaffective disorder in a naturalistic setting in Korean people.

\section{Methods}

\section{Study design}

This study was conducted between April and November, 2007, in 42 centers, with the approval of the appropriate institutional review boards. Minimal inclusion and exclusion criteria were used in order to diminish the potential selection bias. The 860 enrolled patients received a series of evaluations: clinical global impression improvement/severity (CGI-I/CGI-S), drug dosage, drug compliance, CGI-5 factor ${ }^{20}$ and patient's satisfaction questionnaire. This evaluation was performed at baseline, at week 2, 4 and then monthly until the end of the study (24 weeks).

During the study, the patients received the recommended dose of quetiapine (150-750 mg/d), but the dose could be increased beyond the recommended dose according to investigator's decision. There were no limitations on patients' concomitant medication use.

\section{Patients}

Each participant gave informed written consent before entering the study. The investigators offered entry to patients with a clinical diagnosis of schizophrenia or schizoaffective disorder (DSM-IV) who were between the ages of 18 and 65 and, in the opinion of the investigators, did not have any other serious medical conditions.

Patients were ineligible for the study if they met any of the following exclusion criteria: 1) a clear history of serious adverse events due to quetiapine; 2) a clear history of non-response of quetiapine, in the investigators' judgment; 3) inadequately controlled diabetes; 4) clinically significant, severe neutropenia with an absolute neutrophil count below 1,500/mm3; 5) simultaneously participation in another clinical trial; and 6) probable non- compliance with the visit schedule or other study procedures, based on the investigators' opinion.

\section{Effectiveness evaluations}

We assessed the quetiapine's treatment effectiveness using the CGI-I and CGI-S. Because there was little chance of improvement in patients with mild symptoms at baseline, we stratified the patients into two groups, mild or severe, using baseline severity as measured by the CGI-S, and evaluated the effectiveness of quetiapine based on the response rate of severe group's response rate and aggravation rate of the mild group. The severe group consisted of patients who were moderately ill or worse (CGI-S $\geq 4$ ) at baseline, with the mild group consisting of the remaining patients. In addition, we defined response rate as the percentage of patients in the severe group having a CGI-I score of 2 or less on any visit ("very much improved" or "much improved"). In the mild group, we defined the aggravation of symptoms as a CGI-I score $\geq 5$ on any visit during the study.

The intention to treat (ITT) population included all patients who received at least one follow-up evaluation. Missing data for the ITT population were imputed using the last observation carried forward (LOCF) method. Primary objective of this study was to investigate the effectiveness of quetiapine by analyzing the response rate in the ITT population using the LOCF and the Kaplan-Meier (K-M) method to estimate the probability of response at 24 weeks, including the inverse of the survival curve. Our secondary objectives were to explore the relationship between quetiapine dosage pattern and patient response rate, time to response, and changes in the CGI-5 factor's subscale scores: positive, negative, depressive, excitement, and cognitive subscale.

\section{Data analysis}

We performed the statistical analyses using SAS version 9.1 for Windows (SAS Institute Inc., Cary, NC, USA), described continuous variables using summary statistics, such as means, standard deviations, and ranges, and described categorical variables using frequencies and percentages. For the analysis of effectiveness, we estimated the response rate of patients in severe group using the LOCF and the K-M method. We used the K-M method to estimate the cumulative rate of response in consideration of the patients' high dropout rate due to the longterm follow-up. To analyze continuous changes from baseline, we used paired t-tests. Statistical significance was defined by $\mathrm{p}<0.05$. All tests were two sided.

\section{Results}

\section{Patient disposition and demographics}

Of the 860 patients enrolled in this study, 821 patients received at least one follow-up evaluation; these comprised the ITT population for the effectiveness analyses (Figure 1). The 
mean age of the ITT population was 39.5 years (range: 18-65 years), and $45.4 \%(n=373)$ were male. One hundred ninetythree patients (23.5\% of the ITT population) had never received any prior antipsychotic medications (Table 1).

During the 24-week follow-up, 151 patients (18.4\%) dropped out of the study; $62.9 \%$ of these dropouts left within 8 weeks. The most common reasons for the discontinuation from the study were follow-up loss (35.1\%), lack of efficacy or withdrawal of consent $(27.8 \%)$, and lack of compliance (12.6\%). Dropout patients' CGI-S scores at baseline were significantly higher than those of patients who completed the study $(4.8 \pm 1.0$ and $4.4 \pm 1.1$, respectively; $\mathrm{df}=819, \mathrm{t}=-3.3, \mathrm{p}=$ $0.001)$.

There was no prohibition of the concomitant use of psychotropic medications during the study, including the use of antipsychotics, and $53.6 \%-57.5 \%$ of the study population received at least one concomitant psychotropic medication at each visit during the study. The percentages who received antianxiety or anticholinergic drugs during the study were $24.0 \%-27.2 \%$ and $13.3 \%-16.1 \%$, respectively. The percentages for concomitant use of antipsychotics was 9.1\% (at baseline), $12.3 \%$ (maximum rate during the study), and $11.8 \%$ (at 24 weeks).

\section{Effectiveness analyses}

There was a significant decrease in mean CGI-S score, from $4.5 \pm 1.1$ at baseline to $2.8 \pm 1.1$ at 24 weeks (LOCF, paired t-test; $\mathrm{df}=820, \mathrm{t}=-36.3, \mathrm{p}<0.001)$. Because there was little chance of improvement in patients with mild symptoms at baseline, as described detail in the method section, all patients in the ITT group were divided into 2 groups according to baseline CGI-S score: the severe group ( $\mathrm{n}=670$, CGI-S $\geq 4$ ) and the mild group ( $n=151, \mathrm{CGI}-\mathrm{S} \leq 3)$. When estimated by the LOCF and the K-M method, the severe group's response

\begin{tabular}{|c|c|}
\hline Visit 1 (week 0) & \\
\hline \multicolumn{2}{|l|}{ Enrolled patients at baseline } \\
\hline$\downarrow$ & $\nabla$ \\
\hline Visit 2 (week 2) & $\mathrm{N}=39$ \\
\hline $\begin{array}{l}\text { Patients who were received at } \\
\text { least one more evaluation }\end{array}$ & $\begin{array}{l}\text { Excluded from the analysis of } \\
\text { effectiveness and tolerability }\end{array}$ \\
\hline $\mathrm{N}=821$ & \multirow[b]{2}{*}{$\downarrow$} \\
\hline$\nabla$ & \\
\hline Visit 8 (week 24) & $\mathrm{N}=151$ (Drop out patients) \\
\hline Patients completed the study & - Follow-up loss $(35.1 \%)$ \\
\hline $\mathrm{N}=670$ & - Lack of efficacy, withdrawal of consent $(27.8 \%)$ \\
\hline & - Lack of compliance (12.6\%) \\
\hline & - Others $(21.9 \%)$ \\
\hline
\end{tabular}

Figure 1. Disposition of participated patients in the study.

Table 1. Demographic characteristics of enrolled patients $(\mathrm{N}=821)$

\begin{tabular}{|c|c|c|c|}
\hline & & & [Min-Max \\
\hline Age & (Mean $\pm \mathrm{SD}$, year) & $39.5 \pm 12.1$ & {$[18-65]$} \\
\hline \multirow[t]{2}{*}{ Gender } & Male & 373 & $45.4 \%$ \\
\hline & Female & 448 & $54.6 \%$ \\
\hline Onset age* & (Mean $\pm S D$, year) & $29.6 \pm 9.6$ & [14-63] \\
\hline \multirow[t]{5}{*}{ Diagnosis } & Schizophrenia, paranoid type & 395 & $48.1 \%$ \\
\hline & Schizophrenia, catatonic type & 3 & $0.4 \%$ \\
\hline & Schizophrenia, residual type & 49 & $6.0 \%$ \\
\hline & Schizophrenia, undifferentiated type & 209 & $25.5 \%$ \\
\hline & Schizoaffective disorder & 165 & $20.1 \%$ \\
\hline \multirow{2}{*}{$\begin{array}{l}\text { Taking any antipsychotics } \\
\text { before entering the study }\end{array}$} & Yes & 627 & $76.5 \%$ \\
\hline & No & 193 & $23.5 \%$ \\
\hline
\end{tabular}

Total number of patients: ${ }^{*} \mathrm{~N}=775,{ }^{\dagger} \mathrm{N}=820$ 
rates at 24 weeks were $54.5 \%$ and $73.3 \%$, respectively [ $(95 \%$ confidence interval (CI); 69.5\%-77.1\%)](Figure 2). At 24 weeks, most patients in the mild group $(n=148,98.0 \%$, LOCF) showed no clinically significant aggravation of symptoms.

Analysis of CGI-5 factors in ITT group showed that all the subscale scores of CGI-5 factors such as positive, negative, cognitive, depressive, and agitation domains significantly decreased between baseline and 24 weeks (Table 2).

\section{Dose-effectiveness relationship}

The mean doses prescribed to the patients were $244.7 \mathrm{mg} / \mathrm{d}$ on day 1 and $305.2 \mathrm{mg} / \mathrm{d}$ on day 4 . After that, the mean dose increased to a peak dose of $537.8 \mathrm{mg} / \mathrm{d}$ at 8 weeks and then decreased slowly, to $508.3 \pm 245.75 \mathrm{mg} / \mathrm{d}$ at 24 weeks (Table 3 ). The patients who completed the study took a mean dose of $507.9 \pm 245.9 \mathrm{mg} / \mathrm{d}$ daily over the course of the study (minimum 12.5-maximum 1,500 mg/d).

In the severe group, there was no significant difference in mean quetiapine dosage between responders and non-responders $(536.9 \pm 217.9$ and $567.9 \pm 247.5 \mathrm{mg} / \mathrm{d}, \mathrm{LOCF}$, respectively; $\mathrm{df}=557, \mathrm{t}=-1.66, \mathrm{p}=0.098$ ).

To evaluate the effectiveness of quetiapine dosages above the recommended, we compared the changes in CGI-S between the high-dose group (maximum dose $750 \mathrm{mg} / \mathrm{d}$ or above) and the recommended-dose group (maximum dose less than $750 \mathrm{mg} / \mathrm{d}$ ). From baseline to 24 weeks, the CGI-S scores in the

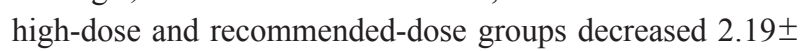
1.44 and $1.70 \pm 1.29$, respectively, and these changes were significantly different between the groups after controlling for baseline CGI-S scores (ANCOVA; covariate-age, baseline CGI$\mathrm{S} ; \mathrm{F}=-3.79, \mathrm{p}<0.001)$. Mean doses during the study for the highdose and recommended-dose groups were 745.2 \pm 164.7 and $392.1 \pm 169.3 \mathrm{mg} / \mathrm{d}$, respectively. In addition, we further stratified the patients based on mean quetiapine dose during the study. The CGI-S scores of patients prescribed a mean dose of $\geq 750 \mathrm{mg} / \mathrm{d}$ were significantly decreased compared with those of patients prescribed a mean dose of $<750 \mathrm{mg} / \mathrm{d}$ (ANCOVA; covariate-age, baseline CGI-S; $\mathrm{F}=-4.42, \mathrm{p}<0.001$ ).

\section{Patients' satisfaction}

We assessed the patients' satisfaction with quetiapine at 4, 12 , and 24 weeks. There was a trend for patients' satisfaction to gradually increase. The proportion of patients who expressed "very much satisfaction" increased from $17.0 \%$ at 4 weeks

Figure 2. The estimated cumulative response rate of patients during 24 weeks follow-up using Kaplan-Meier method.

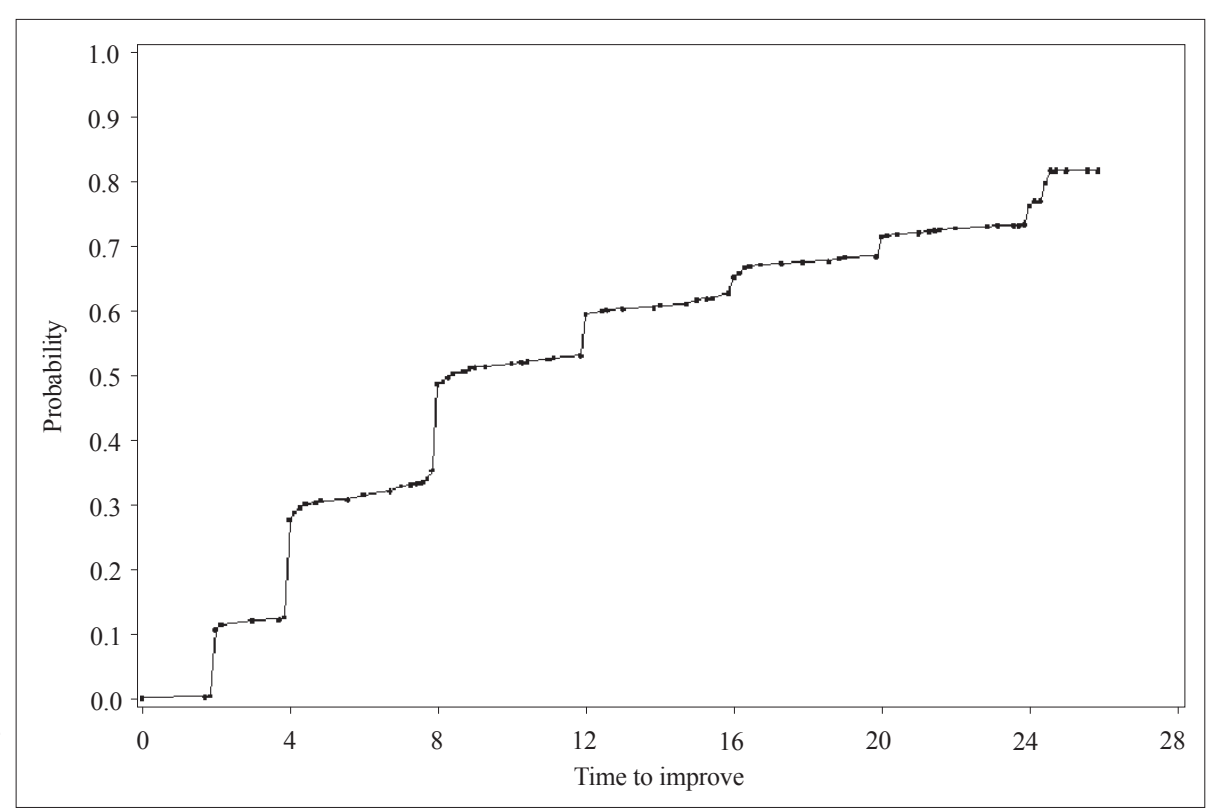

Table 2. The changes of clinical global impression- 5 factor from baseline to 24 weeks

\begin{tabular}{|c|c|c|c|c|c|c|}
\hline & \multirow{2}{*}{$\mathrm{N}$} & \multirow{2}{*}{$\begin{array}{c}\text { Baseline } \\
\text { Mean } \pm \text { SD }\end{array}$} & \multirow{2}{*}{$\begin{array}{l}\text { End point } \\
\text { Mean } \pm \text { SD }\end{array}$} & \multicolumn{3}{|c|}{ Statistical value } \\
\hline & & & & df & t-value & p-value* \\
\hline Positive & 791 & $4.27 \pm 1.27$ & $2.47 \pm 1.13$ & 790 & -36.12 & $<0.0001$ \\
\hline Negative & 789 & $3.23 \pm 1.27$ & $2.29 \pm 1.00$ & 788 & -20.55 & $<0.0001$ \\
\hline Depression & 791 & $3.08 \pm 1.27$ & $2.08 \pm 1.01$ & 790 & -21.11 & $<0.0001$ \\
\hline Cognition & 788 & $3.05 \pm 1.35$ & $2.05 \pm 1.03$ & 787 & -22.55 & $<0.0001$ \\
\hline Excitation & 787 & $3.38 \pm 1.54$ & $1.84 \pm 1.00$ & 786 & -28.37 & $<0.0001$ \\
\hline
\end{tabular}

*Paired t-test using the last observation carried forward method 
Table 3. Treatment dose of quetiapine at any visit $(\mathrm{mg} / \mathrm{d})$

\begin{tabular}{|c|c|c|c|c|c|}
\hline & $\mathrm{N}$ & Mean \pm SD & Median & Min & Max \\
\hline Visit1 (baseline) & 820 & $231.30 \pm 179.54$ & 200 & 12.5 & 1,000 \\
\hline Visit2 (2 weeks) & 779 & $451.70 \pm 258.50$ & 400 & 25 & 1,600 \\
\hline Visit3 (4 weeks) & 760 & $525.87 \pm 267.83$ & 550 & 12.5 & 1,800 \\
\hline Visit4 (8 weeks) & 754 & $537.78 \pm 261.74$ & 600 & 12.5 & 1,800 \\
\hline Visit5 (12 weeks) & 721 & $532.99 \pm 246.98$ & 600 & 12.5 & 1,400 \\
\hline Visit6 (16 weeks) & 695 & $526.31 \pm 241.30$ & 600 & 12.5 & 1,200 \\
\hline Visit7 (20 weeks) & 678 & $519.45 \pm 242.18$ & 500 & 12.5 & 1,500 \\
\hline Visit8 (24 weeks) & 665 & $508.33 \pm 245.75$ & 500 & 12.5 & 1,500 \\
\hline
\end{tabular}

Table 4. Patients' satisfaction with quetiapine

\begin{tabular}{|c|c|c|c|c|c|c|}
\hline & Visit3 & Visit5 & Visit8 & \multirow{2}{*}{$\mathrm{df}$} & \multirow{2}{*}{$\mathrm{CMH}$ value } & \multirow{2}{*}{ p-value* } \\
\hline & $\mathrm{N}(\%)$ & $\mathrm{N}(\%)$ & $\mathrm{N}(\%)$ & & & \\
\hline Very much & $126(17.03)$ & $200(28.90)$ & $260(40.25)$ & \multirow{5}{*}{1} & \multirow{5}{*}{188.97} & \multirow{5}{*}{$<0.0001$} \\
\hline Moderately & $226(30.54)$ & $298(43.06)$ & $270(41.80)$ & & & \\
\hline Minimally & $321(43.38)$ & $178(25.72)$ & $108(16.72)$ & & & \\
\hline Not at all & $67(9.05)$ & $16(2.31)$ & $8(1.24)$ & & & \\
\hline Total & $740(100.00)$ & $692(100.00)$ & $646(100.00)$ & & & \\
\hline
\end{tabular}

${ }^{*}$ Cochran-Mantel-Haenszel (CMH) test (comparison of visit3 and visit8)

to $40.3 \%$ at 24 weeks (Table 4 ). In addition, the patients' satisfaction at 24 weeks significantly increased compared with that at 4 weeks using Cochran-Mantel-Haenszel test $(\mathrm{df}=1, \mathrm{CMH}$ value $=188.97, \mathrm{p}<0.0001$ ).

\section{Discussion}

This naturalistic study showed the effectiveness of quetiapine to treat schizophrenia or schizoaffective disorder. The response rates of patients in the severe group were $54.5 \%$ and $73.3 \%$ when estimated by the LOCF and the K-M method, respectively. The fact that some patients experienced worsening symptoms (CGI-I >3) after having once shown a positive response (CGI-I $\leq 2)$ at any visit, which means the K-M method counted these patients $(n=154,18.8 \%)$ in its response group but the LOCF included them in the non-response group, might explain this difference in response rates. The analysis, using LOCF imputation, was performed to estimate the response rate based on the CGI-I score at end point, irrespective of CGI-I scores before the end point. But K-M was performed to estimate the response rate based on the CGI-I score at any visit; therefore, the response rate using the K-M method would generally be higher than that using the LOCF. However, although $18.8 \%$ of patients showed a worsening of symptoms after they had shown a positive response at any one visit, the symptoms did not worsen to any serious extent. About $90 \%$ of worsened patients had CGI-S scores of 3 (mild) or lower at study's end. In addition, quetiapine was effective to treat the patients in the mild group. Only $2 \%$ of patients in the mild group experi- enced an aggravation of their symptoms.

To compare the effectiveness of quetiapine to that of the other antipsychotics, we compared our results with the published results of studies with similar protocols. The 26-week, naturalistic, open study by Kerwin et al. ${ }^{21}$ showed that the response rate (CGI-I $\leq 2$, LOCF) were $44 \%$ and $34 \%$ in schizophrenic patients prescribed aripiprazole and another atypical antipsychotic, respectively. According to the European Broad Effectiveness with aripiprazole (EU-BETA) study, 43\% of schizophrenic patients showed positive responses $(\mathrm{CGI}-\mathrm{I} \leq 2)$ during the study's 8-week follow-up period. ${ }^{22}$ These results showed the response rate of quetiapine in our study was similar to that of other antipsychotics. This suggests antipsychotic efficacy of quetiapine is comparable to that of other atypical antipsychotics.

It is generally well-known that, within the recommended dose range, quetiapine is well-tolerated and clinically effective for the treatment of schizophrenia. According to the review of literature by Sparshatt et al., ${ }^{23} 150-450 \mathrm{mg} / \mathrm{d}$ dosages of immediate-release (IR) quetiapine are more effective than placebo treatment. Furthermore, this review showed IR quetiapine dosages averaging between 254 and $525 \mathrm{mg} / \mathrm{d}$ are equivalent in efficacy to standard dosages of both conventional and other atypical antipsychotics. Some studies, however, have reported that higher than recommended doses of quetiapine were more effective in some patients with schizophrenia. Quetiapine dosages above $750 \mathrm{mg} / \mathrm{d}$ have been well-tolerated and effective in some patients. ${ }^{18}$ A 12 -week open label trial of high dose quetiapine for patients with documented treatment-refractory schizophrenia showed that $4(33 \%)$ of the patients responded 
to treatment during the study, in which all patients were titrated to the target dose of $1,200 \pm 200 \mathrm{mg} / \mathrm{d}$ over a three-week period. ${ }^{19}$ These studies showed that the patients receiving higher than recommended quetiapine dosages improved more than did patients receiving the recommended dose. Consistent with these studies, our findings, in which the patients who took more than the recommended dosage (mean or max dose $\geq 750 \mathrm{mg} / \mathrm{d}$ ) improved significantly more than did the patients taking the recommended dose, suggest the possibility that higher than recommended dosages of quetiapine are more effective for treating schizophrenia or schizoaffective disorder.

This study had a general limitation of the open, non-comparative study. Therefore, generalization of the results of this study beyond the sample population should be made cautiously. Another limitation of this study was related to the concomitant use of other antipsychotics in some patients. At any time during the study period, $145(17.7 \%)$ patients (the concomitant group) were concomitantly taking other antipsychotics in addition to quetiapine. Most concomitant antipsychotics during the study were risperidone ( $\mathrm{n}=42,6.06 \pm 9.55 \mathrm{mg}$ /day), olanzapine $(n=9,15.42 \pm 14.23 \mathrm{mg} /$ day $)$ and haloperidol $(n=19,5.64 \pm$ $3.74 \mathrm{mg} /$ day). The number of patients who had taken concomitant antipsychotics at each visit ranged from 76 (at baseline) to 92 (at 2 weeks) during the study. Although the baseline symptoms in the concomitant group were more severe than those in the non-concomitant group, who took quetiapine alone during the study (CGI-S scores $4.79 \pm 1.11$ vs. $4.43 \pm 1.06$; Student's ttest; $\mathrm{df}=819$, $\mathrm{t}=-3.66, \mathrm{p}<0.001$ ), these two groups showed significant improvements over time. Furthermore, the non-concomitant group showed similar symptom improvements when compared to the concomitant group. We obtained these similar results when we reanalyzed the data of patients who did not receive concurrent antipsychotics.

In spite of these limitations, the major implications of this study are as follows: 1) Quetiapine is well-tolerated and effective for treating schizophrenia or schizoaffective disorder in the usual care setting; 2) Dosages of quetiapine above $750 \mathrm{mg} / \mathrm{d}$ may be more desirable than recommended dosages for some patients with schizophrenia or schizoaffective disorder.

-Acknowledgments

This study was funded by AstraZeneka Korea.

\section{REFERENCES}

1. Arvanitis LA, Miller BG. Multiple fixed doses of "Seroquel" (quetiapine) in patients with acute exacerbation of schizophrenia: a comparison with haloperidol and placebo. The Seroquel Trial 13 Study Group. Biol Psychiatry 1997;42:233-246.

2. Borison RL, Arvanitis LA, Miller BG. ICI 204,636, an atypical antipsychotic: efficacy and safety in a multicenter, placebo-controlled trial in patients with schizophrenia. U.S. SEROQUEL Study Group. J Clin Psychopharmacol 1996;16:158-169.

3. Small JG, Hirsch SR, Arvanitis LA, Miller BG, Link CG. Quetiapine in patients with schizophrenia. A high- and low-dose double-blind comparison with placebo. Seroquel Study Group. Arch Gen Psychiatry 1997;54:549-557.

4. Copolov DL, Link CG, Kowalcyk B. A multicentre, double-blind, randomized comparison of quetiapine (ICI 204,636, 'Seroquel') and haloperidol in schizophrenia. Psychol Med 2000;30:95-105.

5. Emsley RA, Raniwalla J, Bailey PJ, Jones AM. A comparison of the effects of quetiapine ('seroquel') and haloperidol in schizophrenic patients with a history of and a demonstrated, partial response to conventional antipsychotic treatment. PRIZE Study Group. Int Clin Psychopharmacol 2000;15:121-131.

6. Velligan DI, Newcomer J, Pultz J, Csernansky J, Hoff AL, Mahurin $\mathrm{R}$, et al. Does cognitive function improve with quetiapine in comparison to haloperidol? Schizophr Res 2002;53:239-248.

7. Bowden CL, Grunze H, Mullen J, Brecher M, Paulsson B, Jones M, et al. A randomized, double-blind, placebo-controlled efficacy and safety study of quetiapine or lithium as monotherapy for mania in bipolar disorder. J Clin Psychiatry 2005;66:111-121.

8. McIntyre RS, Brecher M, Paulsson B, Huizar K, Mullen J. Quetiapine or haloperidol as monotherapy for bipolar mania--a 12-week, doubleblind, randomised, parallel-group, placebo-controlled trial. Eur Neuropsychopharmacol 2005;15:573-585.

9. Altamura AC, Mundo E, Dell'Osso B, Tacchini G, Buoli M, Calabrese JR. Quetiapine and classical mood stabilizers in the long-term treatment of Bipolar Disorder: a 4-year follow-up naturalistic study. J Affect Disord 2008;110:135-141.

10. Sachs G, Chengappa KN, Suppes T, Mullen JA, Brecher M, Devine NA, et al. Quetiapine with lithium or divalproex for the treatment of bipolar mania: a randomized, double-blind, placebo-controlled study. Bipolar Disord 2004;6:213-223.

11. Vieta E, Calabrese JR, Goikolea JM, Raines S, Macfadden W; BOLDER Study Group. Quetiapine monotherapy in the treatment of patients with bipolar I or II depression and a rapid-cycling disease course: a randomized, double-blind, placebo-controlled study. Bipolar Disord 2007;9:413-425.

12. McIntyre RS, Konarski JZ, Jones M, Paulsson B. Quetiapine in the treatment of acute bipolar mania: efficacy across a broad range of symptoms. J Affect Disord 2007;100 Suppl 1:S5-S14.

13. Ketter TA, Jones M, Paulsson B. Rates of remission/euthymia with quetiapine monotherapy compared with placebo in patients with acute mania. J Affect Disord 2007;100 Suppl 1:S45-S53.

14. Thase ME, Macfadden W, Weisler RH, Chang W, Paulsson B, Khan A, et al; BOLDER Study Group. Efficacy of quetiapine monotherapy in bipolar I and II depression: a double-blind, placebo-controlled study (the BOLDER II study). J Clin Psychopharmacol 2006;26:600609.

15. Kahn RS, Fleischhacker WW, Boter H, Davidson M, Vergouwe Y, Keet IP, et al. Effectiveness of antipsychotic drugs in first-episode schizophrenia and schizophreniform disorder: an open randomised clinical trial. Lancet 2008;371:1085-1097.

16. Mullins CD, Obeidat NA, Cuffel BJ, Naradzay J, Loebel AD. Risk of discontinuation of atypical antipsychotic agents in the treatment of schizophrenia. Schizophr Res 2008;98:8-15.

17. Haro JM, Novick D, Suarez D, Alonso J, Lépine JP, Ratcliffe M; SOHO Study Group. Remission and relapse in the outpatient care of schizophrenia: three-year results from the Schizophrenia Outpatient Health Outcomes study. J Clin Psychopharmacol 2006;26:571-578.

18. Arango C, Bobes J. Managing acute exacerbations of schizophrenia: focus on quetiapine. Curr Med Res Opin 2004;20:619-626.

19. Boggs DL, Kelly DL, Feldman S, McMahon RP, Nelson MW, Yu Y, et al. Quetiapine at high doses for the treatment of refractory schizophrenia. Schizophr Res 2008;101:347-348.

20. Kim JY, Kang SH, Kim SJ, Kwak KH, Kim CY. The validity and reliability of brief rating scales for the assessment of symptoms and functions in patients with psychosis. J Korean Neuropsychiatr Assoc 2007;46:492-498 
21. Kerwin R, Millet B, Herman E, Banki CM, Lublin H, Pans M, et al. A multicentre, randomized, naturalistic, open-label study between aripiprazole and standard of care in the management of communitytreated schizophrenic patients Schizophrenia Trial of Aripiprazole: (STAR) study. Eur Psychiatry 2007;22:433-443.

22. Wolf J, Janssen F, Lublin H, Salokangas RK, Allain H, Smeraldi E, et al. A prospective, multicentre, open-label study of aripiprazole in the management of patients with schizophrenia in psychiatric practice in Europe: Broad Effectiveness Trial with Aripiprazole in Europe (EUBETA). Curr Med Res Opin 2007;23:2313-2323.

23. Sparshatt A, Jones S, Taylor D. Quetiapine: dose-response relationship in schizophrenia. CNS Drugs 2008;22:49-68; discussion 69-72. 